\title{
O USO DE MODELO DIDÁTICO COMO FACILITADOR DA APRENDIZAGEM SIGNIFICATIVA NO ENSINO DE BIOLOGIA CELULAR
}

\author{
Elaine Gimenez Guimarães ${ }^{1}$ \\ Lorena Souza Castro \\ Keminy Ribett Bautz ${ }^{3}$ \\ Gustavo Lemos Rocha ${ }^{4}$
}

Resumo: A biologia celular é uma das sub áreas da Biologia mais problemáticas, que desafiam a comunidade escolar. Nesse âmbito, é notável a dificuldade apresentada pelos discentes na compreensão de temas como dimensão celular e funções desempenhadas pelas organelas, sendo necessário o desenvolvimento de estratégias que objetivem ampliar e facilitar discussões dessa natureza. Tendo isso em vista, o presente trabalho relata a utilização de um modelo tridimensional de uma célula eucariota como ferramenta de apoio ao ensino de temas em citologia, assim como uma atividade dinâmica em que foi estabelecida uma analogia entre a célula e uma cidade. Ao fim do processo, foi detectado um melhor rendimento e um aumento no interesse pelo tema por parte dos discentes participantes.

Palavras-chave: Conhecimento prévio; Biologia celular; Aprendizagem significativa.

\footnotetext{
${ }^{1}$ Ciências biológicas/UFES, Brasil. E-mail: elainegimenezg@hotmail.com.

2 Ciências biológicas/UFES, Brasil. E-mail: lorena-sc3@hotmail.com.

${ }^{3}$ Ciências biológicas/UFES, Brasil. E-mail: keminy.ribet@hotmail.com.

4 Doutorando em biociências e biotecnologia/ UENF, Brasil. gustavolrocha@yahoo.com.br.
} 